\title{
The Making of Phenomenology as an Autonomous Discipline
}

\author{
MARCUS SACRINI
}

\section{Introduction}

Husserl presents phenomenology for the first time to his reading audience in Logical Investigations (1900/1901). However, scholars recognize the doctrine presented in Logical Investigations is distinct from the transcendental position Husserl begins to develop systematically around 1905 , which is presented to the reading audience in a remarkably mature form in Ideas Pertaining to a Pure Phenomenology and to a Phenomenological Philosophy I (1913). The passage from the phenomenology of Logical Investigations to transcendental phenomenology includes complex conceptual changes, which have been studied by several commentators. ${ }^{1}$ However, I believe there is a feature of this change that is not completely exhausted and still deserves commentary, namely, the fact that phenomenology from Logical Investigations is not an autonomous discipline, but part of a wide project of founding a general doctrine of science. ${ }^{2}$ This situation contrasts enormously with the role of phenomenology in Ideas I. There, phenomenology is clearly independent not only of any other science, but also of the general doctrine of science, presented as a mathesis universalis. ${ }^{3}$ In this article, I intend to make clear this change in the role of phenomenology as an important step in Husserl's elaboration of his transcendental reflection. Of course, there are other essential aspects implied in the passage to transcendental phenomenology (e,g., the method of reduction, the inclusion of the 
noematic sphere in the field of investigation) and I intend to show some connections with at least some of them. In order to complete these tasks, I plan to discuss two central texts to this change, namely, the Prolegomena to Pure Logic (1900), introductory work to the Logical Investigations, and Introduction to Logic and Theory of Knowledge, a series of lectures given in 1906-7 wherein Husserl proposes a tacit reevaluation of some features of his earlier project outlined in the Prolegomena.

\section{Phenomenology and pure logic}

In this section, I intend to analyze the way Husserl presents phenomenology in the Prolegomena. Phenomenology will be inserted in a general debate concerning the autonomy of logic. Husserl rejects founding logic on psychology and foresees an autonomous logical system (called "pure logic") that would establish the theoretical basis for any scientific discipline. ${ }^{4}$ Let me outline the main traits of pure logic in order to introduce the specifically phenomenological issue in the Prolegomena.

Husserl first examines the manner in which scientific knowledge is obtained. The construction of scientific knowledge is, according to him, supported by logical methods that legitimate the acquisition of mediate knowledge on the basis of basic knowledge (which would be apprehended with immediate evidence). Thus, the examination of these logical methods of validation or foundation (Begründungen) will make clear the general norms for the construction of valid theories in all scientific areas. According to Husserl, the possibility of establishing such norms derives from three characteristics of the general methods of justification or foundation of knowledge (cf. Hua XVIII, §7) ${ }^{5}$ : 
a) they are fixed structures, that is, a non-arbitrary sequence of procedures;

b) these procedures can be used in different kinds of research;

c) their form is independent of the material domain in which they are applied.

The scientific methods of foundation or justification are, thus, sets of fixed procedures whose validity is not connected to the concrete peculiarities of their application, and which are, therefore, formalizable. Such methods constitute the most general theoretical nucleus that renders the development of the different scientific investigations possible. For instance, the use of the axiomatic-deductive method guarantees the extraction of valid conclusions in the sphere of geometry, theoretical physics, and so on. Thus, the study of this kind of method in its formal purity (which includes the categories that compose them and the a priori laws that rule them) circumscribes the domain of the "doctrine of science" [Wissenschaftslehre] (Logical Investigations 16; Hua XVIII 27.) - the investigation of that which gives sciences in general their scientificity. Given that the doctrine of science investigates the formal structures of the methods that constitute the theoretical nucleus of sciences (regardless of the domain to be investigated), Husserl presents it as a logical discipline that aims at delimiting the basic concepts and rules that render every systematic or theoretical unity of knowledge possible (cf. Hua XVIII, §42). This discipline is what Husserl calls pure logic. ${ }^{6}$

Pure logic is then meant to establish the systemic forms and a priori laws that constitute the theoretical nucleus of every possible science. Husserl explicitly resumes here the Leibnizian ideal of a mathesis universalis, that is, of a universal knowledge with mathematical form and rigor (cf. Hua XVIII, §60). ${ }^{7}$ The domain of pure logic is that of formal connections among the basic theoretical categories and propositions ordered in accordance with a priori laws (cf. Hua XVIII, §48). And its general task will partly be to ascend from the different theoretical 
connections valid as foundational methods to the final axioms upon which the systematic connections are based, and partly to make explicit the form of those connections. ${ }^{8}$ The perfect theoretical form revealed by pure logic is the deductive structure based upon axioms and fundamental laws (Logical Investigations 146-7; Hua XVIII 234.). This is the form pure logic itself has, so that it founds itself. In other words, the systematic-deductive form of pure logic is itself governed by the a priori logic laws concerning deductive systematicity, laws that are themselves revealed by pure logic (Logical Investigations 104-5; Hua XVIII 165).

It should be noted that pure logic analyzes not only the basic concepts of scientific methods and their deductive propositional linkages, but also formal properties and relations established among the objects possibly referred to by them. An object, be it empirical or ideal, can be counted, can be put in relationship with similar ones, etc. In this case, one deals with basic characteristics, under which the very notion of object is constructed. The study of such characteristics constitutes a formal ontology, that is, a part of pure logic that analyses the conceptual components of any kind of object that can be referred to by propositions in any conceivable material or ideal domain (cf. Hua XVIII, §70). ${ }^{9}$

Ideal truths and laws established by pure logic are the objective conditions of scientific theories in general. In order to warrant being designated as scientific, every theory must be formally structured according to deductive connections revealed by pure logic. ${ }^{10}$ In addition to this, Husserl enumerates subjective conditions that must be fulfilled for the theoretical-objective content of sciences to be apprehended as knowledge. Every theoretical objective unity must be included in that which subjectivity is able to know. If subjectivity could not recognize the objective character of the components of pure logic, then it would not be possible to develop it as a true logical theory. Accordingly, one must consider the subjective capacities of recognizing 
and attesting truth and objectivity as necessary conditions for the establishment of a doctrine of science. And for Husserl the distinctive characteristic of the subjective experience of rational knowledge is evidence, that is, the clear insight that a certain state of things is or is not what it seems to be. ${ }^{11}$ Evidence is not an accessory feeling contingently added to certain judgments; rather, it is a structural part of a particular kind of experience. To be more precise, every experience of evidence includes the original givenness of what is aimed at in that experience. In Husserl's words, "what is self-evidently judged is not merely judged ... but is given in the experience of judgment as itself present" (Logical Investigations 121; Hua XVIII 193). And this possibility of evident givenness of the truth contained in the judgments making up a theory is, according to Husserl, a basic subjective condition for the establishment of knowledge.

Even pure logic, the universal theory of the forms of possible theories, must respect the subjective conditions of evidence. After all, as Husserl recognizes, the theory of theories is also knowledge, and therefore must be given in an experience of evident cognitive justification (cf. Hua XVIII, §32). However, pure logic in itself, at least as a purely objective mathesis universalis, says nothing about the conditions of its own epistemic justification. Such a mathesis specifies the basic axioms and the a priori valid propositional linkages, which attribute a theoretical form to any scientific investigation, and, in themselves, these axioms and linkages do not refer to the cognitive subject. Accordingly, it is necessary to complement pure logic with another kind of investigation, which addresses the evident givenness of the objective content of theories to the cognitive subject. It is exactly here that the specificity of phenomenological investigation becomes clear, that is, it is exactly from the need of correlating logical truths and laws defined as objectively valid with the cognitive subject that the phenomenological set of problems will be brought together for the first time. 
One must not fail to notice that Husserl distinguishes between what is subjective and should be phenomenologically investigated, and what is psychological, in the sense of particular and empirical. Thus, in referring to subjective conditions of theories, Husserl does not point to the empirical experiences of concrete subjects either individually or even taken as human species. No such real particularities of existing human beings must be considered as a priori conditions of knowledge. The subjective conditions investigated by phenomenology share ideality with the logical-objective domain, that is, they are valid conditions not because they mark singularities of factual human existence, but because they distinguish certain a priori structures which constitute the form or the essence of subjectivity independently of its occurrence in past, present or future human beings. To avoid confusion with the empirical constraints of human activity, Husserl calls these ideal subjective conditions, relative to the $a$ priori essence of subjectivity, noetic. $^{12}$

The analysis of the noetic conditions of theories will not be a task for experimental or empirical psychology. For Husserl, empirical psychology is a science that investigates facts of human psychic life, and therefore relates to certain empirical constraints through which some real possibilities (some facts, some states of things) occur. By contrast, noetic conditions are related to structures that allow the evident apprehension of objective data. These structures determine certain possibilities of evident givenness of the themes in question, and these possibilities are ideal, that is, their a priori validity does not mix with that of real situations, which are contingent. Husserl gives an example of the ideal possibilities: "there are decimal numbers with trillions of places, and there are truths relating to them. No one, however, can actually imagine such numbers, nor do additions, multiplications etc., relating to them. Inward evidence is here a psychological impossible, yet, ideally speaking, it undoubtedly represents a 
possible state of mind" (Logical Investigations 118; Hua XVIII 188). This example shows that although some topics exceed the actual capacities of the human mind, it is still possible to consider them from the point of view of their subjective conditions, that is, from the point of view of the conditions of their evident givenness, even if such conditions have no relation to the real human subjectivity. Empirical psychology studies the real conditions of lived experiences and, thus, explains the causal connections whereby such experiences begin, change and end. However, besides such real conditions, Husserl focuses on ideal subjective conditions, which do not refer to the actual subjects but to the structures of any possible consciousness, to the general form of subjectivity.

The description of the noetic conditions of pure logic is the first phenomenological task formulated by Husserl in his work as a whole. ${ }^{13}$ The term "phenomenology," although present in the writings of several authors of the time, ${ }^{14}$ was fixed in an unmistakable way (becoming the name of a method and a particular doctrine) only in the Prolegomena to Pure Logic. More precisely, in the first edition of this text the term appears only once, in a footnote in which Husserl marks the specificity of his investigation by excluding "the descriptive phenomenology of internal experience" from the field of empirical psychology (Logical Investigations 319; Hua XVIII 215). In the second edition (published in 1913, when transcendental phenomenology was already well-established) Husserl rephrases that sentence so as to further clarify his position: "I sharply distinguish empirical psychology from phenomenology that underlies it" (Logical Investigations 319; Hua XVIII 215n). Next, in the text of the second edition, he explains the meaning of this new kind of investigation: phenomenology should be "taken as a pure theory of the essences of experiences" (Logical Investigations 319; Hua XVIII 215n), which means that phenomenology should describe lived experiences not as factual experiences causally extending 
in the empirical time flow, but as pure experiences, that is, as forms or essences of noetic structures independent of their concrete realization. The phenomenological task is to specify these forms, so as to establish an a priori doctrine of the components of the domain of pure cognitive subjectivity. Accordingly, phenomenology is concerned not with the empirical psychic diversity of subjects in different knowledge situations, but with pure subjective structures or, in another formulation, with intentional essences (cf. Logical Investigations 112; Hua XVIII 178). This intentional character of noetic structures indicates that they are not isolated entities, but that they are always directed to some content. In the Prolegomena, Husserl is interested in unveiling the intentional structures related to the objective components of pure logic. This aim is clearly formulated in a passage added in the second edition of the Prolegomena. In $§ 67$ Husserl specifies that the achievement of the tasks of pure logic (for instance, the determination of the pure categories of signification and their deductive valid linkages) demands going back to the "phenomenological origin" (Logical Investigations 153; Hua XVIII 246); ${ }^{15}$ in other words, it demands clarifying how such categories can be evidently given to the noetically considered subjectivity.

This reference to the noetic origin makes up the core of Husserl's first conception of the tasks of phenomenology. According to him, mathematicians are responsible for developing the logical-objective content of pure logic. However, they do their work without ever questioning the subjective principles that guarantee the legitimacy of their theories, that is, without being concerned about clarifying the conditions of their evident apprehension. ${ }^{16}$ The philosopher should therefore complement the mathematician's work with an investigation of those subjective structures that allow the evident recognition of mathematical results. Philosophy thus performs the work of a "critique of knowledge" (Logical Investigations 160; Hua XVIII 256), that is, a 
clarification of the subjective sources that attribute legitimacy and therefore rationally justify objective knowledge. It is then the task of philosophy to investigate the noetic conditions of the objective mathesis universalis, to investigate, in their eidetic purity, the intentional structures that grant access to logical idealities.

This is the project formulated in the Prolegomena, which is to be completed in Logical Investigations. In the Prolegomena Husserl only outlines the domain of pure logic and recognizes the need to complement this objective doctrine of science with the phenomenological description of the acts in which knowledge is obtained, a description that is gradually presented throughout the following six investigations. It is true that this complementation of pure logic is intended to function as a phenomenological foundation of the doctrine of science. As we have seen, pure logic does not deal with the subjective conditions of its own affirmation as a true theory. And it is necessary here to appeal to a phenomenological investigation of the noetic structures in order to establish the epistemic legitimacy of pure logic. Despite this important role ascribed to phenomenology in the Prolegomena, some years later, in Introduction to Logic and Theory of Knowledge (hereafter, ILTK), Husserl admits that noetic analyses (identified in the Prolegomena with phenomenology in general) do not form an autonomous discipline, since they are dependent on pure logic. This dependence appears as a limitation in reference to the general task of clarifying all possible knowledge, a task taken up by Husserl in ILTK that leads him to develop the transcendental phenomenology, as I intend to make explicit in the next section.

\section{Phenomenology as a universal science of pure consciousness}

Initially, in ILTK, Husserl reproduces the path of the Prolegomena. In the first section of his 1906-7 lectures, he emphasizes that logical methods of justification are independent of the 
scientific domains in which they are applied, which makes it possible to thematize them in an autonomous manner. It is precisely by examining and establishing these methods in their general theoretical aspect that the doctrine of science is constituted as a discipline directed to the formal structures embodied in particular scientific investigations (Hua XXIV, §10). The doctrine of science is supposed to investigate the basic methods of the foundation of knowledge, their components and their a priori laws, irrespective of their concrete realization in empirical reality.

Also reproducing the argumentative movement of the Prolegomena, in the second section of ILTK Husserl presents the noetic analysis as a complement to this objective doctrine of science. The circumscription of the formal elementary components of every theoretical investigation and of the general characteristics of the correlated objective domains is not enough to provide us with a complete doctrine of what constitutes scientificity. After all, the consequences drawn according to the methods of validation established by logic should be rationally justified to the cognitive subject. Certain argumentative moves must appear as valid in contrast with others, whose conclusions are not justified. The problem is then to examine the subjective acts in which such a rational justifying character manifests itself, so as to clarify, from the cognitive subject's point of view, how logical validity is recognized. The objective of noetic analysis is precisely to unveil the essences of subjective acts of knowledge from the point of view of their claims of legitimacy. Its aim is to make explicit for the cognitive acts (e.g., perception, memory, inference) the conditions of a justified manifestation of a particular content as opposed to the mere presumption of reaching valid results. The conditions under consideration here are those founded upon the a priori essence of the acts, regardless of any factual or psychological restrictions on the empirical use of cognition. 
The interesting point, compared to the Prolegomena, appears when Husserl states that the investigation of those noetic subjective conditions does not exhaust the questions related to the phenomenology of knowledge. There would be then "deeper layers of problems of our theory of justification of knowledge" (ILTK 137; Hua XXIV 139). These layers exceed the sphere of noetic analysis as presented until then, and are connected to problems of "transcendental philosophy, those most difficult of all scientific problems in general," and also to "the most important of all problems" (ILTK 137; Hua XXIV 139). Thus, describing the noetic structures that justify and guarantee the right of legitimate apprehension of the principles of pure logic "does not yet mean ... understanding the meaning and possibility of knowledge that is valid, therefore, really aiming at objectivity" (ILTK 139; Hua XXIV 141). And it is exactly this general problem of the possibility of knowledge, already established by Kant as the central theme of transcendental philosophy, which will lead Husserl to develop a philosophical program wider than that of noetic analysis, which, as we have seen, was associated with phenomenology in the Prolegomena.

It is important to notice that the problem of the possibility of knowledge was already tackled by pre-transcendental phenomenology. In the introduction of Logical Investigations, Husserl claims that the following analyses address general problems deriving from epistemology, such as the relation between the "in itself" character of the known object and the "subjective" character of the resulting knowledge (Logical Investigations 169; Hua XIX/I 12-13). Here Husserl clearly touches on the general topic of the possibility of knowledge. However, taking such general problems into consideration does not mean transgressing the limits of phenomenology drawn by the Prolegomena, namely, the epistemic clarification of pure logic, as I shall explain now. 
In the introduction of Logical Investigations Husserl holds that the doctrine of science presented in the Prolegomena as pure logic includes "all a priori, categorial knowledge, in the form of systematic theories" (Logical Investigations 178; Hua XIX/I 27). That means that the categorical structure of any possible knowledge is covered by the system of objective concepts studied by pure logic. And in correlation with this all-encompassing theory of all theories, Husserl conceives a "formal theory of knowledge," that is, an epistemological analysis that precedes any empirical exercise of knowledge, and refers to its widest structures. Accordingly, parallel to the scope of pure logic (which includes the categorical forms of connection valid for the establishment of knowledge in any possible domain), this general noetic investigation will eventually touch upon the problem of knowledge from the point of view of its general possibility, that is, from the point of view of the relation between subjective acts and anything that presents itself as an object. However, this problem will be addressed, in the context of Logical investigations, as a consequence of what Husserl calls the "great task" of this book, namely, "to bring the ideas of logic, the logical concepts and laws, to epistemological clarity and definiteness" (Logical Investigations 168; Hua XIX/I 9). The problem of the possibility of knowledge is, thus, dependent on the clarification of pure logic. It is true that the concepts of pure logic are so wide that they are involved in the production of knowledge in any scientific field, and, in this sense, by clarifying phenomenologically these concepts one deals with global conditions of knowledge. However, this general investigation of knowledge is not an autonomous program in Logical Investigations. This is not the case in ILTK, where Husserl offers a new development of such a problem, independent of the noetic analysis of pure logic.

The transcendental investigations sketched in ILTK focuses on the possibility and meaning of objective knowledge in general. This transcendental possibility is, no doubt, taken 
for granted by scientific investigations, but it does not belong to the explicit content of any scientific theory. According to Husserl, it is the task of philosophical investigation to "inquire reflectively into the subjective sources and ultimate questions about the meaning and possibility of an objectivity constituting itself subjectively" (ILTK 161; Hua XXIV 163). After this elucidation, sciences will not become more or less certain, but at least "thoroughly understandable" (ILTK 186; Hua XXIV 189), in what concerns their meaning and possibility. In this way, transcendental analysis is not a part of scientific theories but it is a kind of reflection that is done in a different level regarding all sciences.

Here one has to notice that the independence of philosophy in regard to scientific results also applies to pure logic. For Husserl, even pure logic, in its formal-objective dimension, is constructed naively in that which concerns the problem of the possibility of knowledge. The objects of pure logic are the logical idealities, which are posited in their objectivity without the clarification of the subjective conditions that make possible the recognition of such an objectivity. According to Husserl, the mathematicians, who should develop pure logic,

do not need ultimate clarity about the meaning, limits, and sources of the objective validity of what is mathematical. They are oriented towards the mathematical as a preestablished objective. They do not inquire reflectively into the subjective sources and ultimate questions about the meaning and possibility of an objectivity constituting itself subjectively. (ILTK 161; Hua XXIV 163)

In pure logic, as in every other science, the tools of research and reflection are turned to the objects to be investigated, certain theses are formulated, and with them theories are constructed, in which the knowledge of such objects is systematized. In this naive way of proceeding "one thinks, knows, and works scientifically without investigating the principles upon which meaning, legitimacy, the source of truly objective validity ultimately everywhere hinge" (ILTK 162; Hua XXIV 164). That is what Husserl calls "the attitude of natural thinking" (ILTK 182; Hua XXIV 
185), or simply, as he calls it in The Idea of Phenomenology, the "natural attitude" (Idea 15; Hua II 17). ${ }^{17}$

By contrast, the transcendental question of the possibility of knowledge is developed outside of the natural attitude of thought. Husserl imagines the possibility of a complete development of the theories of pure mathematics, so as to exhaust in perfectly finished scientificity the entire domain it should investigate. Even in this case, "the problems of critique of knowledge would, though, still be precisely the same" (ILTK 186; Hua XXIV 190), for the theoretical perfection of pure mathematics "would be a fact and nothing more. Upon reflection, it would be a problem" (ILTK 186; Hua XXIV 190). That is, philosophical reflection would not be satisfied even with exhaustive objective knowledge of a domain, because it is interested not in the fact of establishing or stating knowledge, but in the problem of its correctness, or, in other words, in the pure possibility of establishing valid relations between subjectivity and objectivity.

In the last two paragraphs, I tried to show that the transcendental investigation is developed independently of the objective production of knowledge by the sciences, pure logic included. It should be noted now that Husserl does not consider noetic analysis to be autonomous regarding pure logic. As Husserl admits in ILTK, "formal logic and noetic logic are most intimately connected. The former can certainly be worked on independently of the latter, but not the other way around" (ILTK 156; Hua XXIV 158). Such dependence results from the fact that noetic analysis aims at making explicit the subjective acts in which the contents of pure logic can be stated in a justified manner, a task that supposes the previous development of logical themes to which this analysis is applied. Noetic investigations are, therefore, always correlated with what was objectively developed by the logicians or mathematicians who work in the field of pure logic. 
One can already find this dependence in the Prolegomena, especially in $\S 71$, where Husserl presents a division of the tasks that compose the doctrine of science. Mathematicians would develop the objective topics of pure logic (formalization of the methods of validating knowledge and formulation of their general laws) and the philosophers, by means of the phenomenological method, would make explicit the eidetic subjective structures that attest to the validity of such objective topics. According to this way of presenting the tasks of the doctrine of science, philosophers receive their starting point from mathematicians, and, in this sense, the development of objective, pure logic conditions the noetic analyses. But this is not the case in transcendental investigation, which must be developed in an autonomous way in regard to the concrete development of pure logic and sciences in general.

According to Husserl, the first step to developing a transcendental investigation is to exclude all objective knowledge (including that which constitutes pure logic) from the inquiry. As Husserl explains it, "no naturally obtained scientific result is free of [unclarity]. Therefore, we cannot use any as a premise out of which to derive what we are looking for: the answer to these questions" (ILTK 174; Hua XXIV 177). Here the epoché (the suspension of judgment regarding the validity of all scientific knowledge previously given in experience) is performed (Hua XXIV, §33b). Thus, the transcendental critique of knowledge is not based upon any scientific knowledge, and, accordingly, scientific achievements or findings do not contribute in any respect to addressing such a critique. As the aim is to clarify how the relation between subjectivity and objectivity is possible, one should not use as a starting point any knowledge in which such possibility is taken for granted, since, unlike the naive man, the phenomenologist should make explicit this possibility, and not produce objective knowledge using it as an implicit premise. It means here that the philosophical investigation is no longer dependent on the 
progress of pure logic. Like any other scientific theory, pure logic will have its objective validity suspended and their results cannot be a presupposition of the transcendental inquiry ${ }^{18}$.

Through the epoché, Husserl suspends the validity of all scientific judgments and of all objectivity posited by them. What is left is precisely the phenomenon of science, the set of theories composed by claims intended to be true. ${ }^{19}$ A reduction of all activity of knowledge to that which manifests itself in a purely phenomenal way is performed here, without any assumption about the objectivity of what is supposedly known. Husserl then completes the "phenomenological reduction" (ILTK 206; Hua XXIV 211), that is, the disclosing of the pure phenomenality, which resists the epoché. ${ }^{20}$

Husserl aims at establishing, by means of the phenomenological reduction, a sphere of absolutely evident data, a sphere where the subjective conditions (that must be fulfilled in order for something to appear) can be clarified. This sphere is that of "genuine immanence" (ILTK 216; Hua XXIV 219) which is defined by the exclusion of all transcendence, that is, of all nonclarified positing of objectivity. ${ }^{21}$ It is, no doubt, a "limited sphere" (ILTK 234; Hua XXIV 238), constructed by the methodic application of the phenomenological reduction. But in it, Husserl believes, "absolute knowledge is attainable and the critique of reason is practicable" (ILTK 234; Hua XXIV 238).

Absolute knowledge, in this case, is that whose own sources of possibility are clarified. ${ }^{22}$ The data obtained by means of the phenomenological reduction would be free of any transcendent presupposition concerning their objective existence (which is suspended by epoché). Such data are reduced to their pure appearing to consciousness and, if properly described, they allow us to acquire insight about the general subjective conditions that must be fulfilled for something to be known. In the sphere of pure phenomenal data, Husserl believes, 
"one can then wait and see what corresponds to epistemological concepts like being, truth, and so on ... what their obvious, absolutely clear meaning is there. And afterward their meaning can be established, only with the proviso that it may have a narrower meaning" (ILTK 191; Hua XXIV 195). Phenomenological reduction, thus, constitutes a methodically modified dimension in which one can clearly grasp the way the basic concepts related to knowledge operate independent of any transcendence (in the sense of ontological positing of objectivity). In this genuine dimension of immanence, it would be possible to clarify all the main concepts and operations through which knowledge is acquired, so as to establish a kind of model to understand the acquisition of knowledge in general by all sciences.

Here one must notice that the sphere of genuine immanence encompasses phenomena and acts of thought not only related to the realm of knowledge, but which also cover the most diverse activities of the subjective life. In fact, the entire experience of the world, as presented in reduced phenomena, could be the theme of an investigation aimed at clarifying the subjective infrastructure that makes it possible. "How far does the term phenomenology extend then?" Husserl asks himself. "Obviously, as far as the possibility of a purely immanent investigation bracketing out all transcendent extends. We can say: it is the universal science of pure consciousness" (ILTK 215; Hua XXIV 219). Here, anticipating Ideas I, Husserl sketches the passage from an inquiry limited to the epistemic problem to a universal transcendental investigation of pure consciousness in its full depth. ${ }^{23}$

Transcendental phenomenology can now be conceived of as the science intending to examine the correlative eidetic structures (involving subjective acts and pure phenomena) comprising the general meaning of any lived experience. Its task is to reflexively investigate the eidetic laws regarding pure subjective capacities and their intentional objects. These laws can be 
examined for any phenomenologically reduced experience, and this certainly includes the sphere of logical knowledge, such as circumscribed in the Prolegomena. Thus, the task of clarification of pure logic is assumed by Husserl's transcendental project. However, it is important to highlight that transcendental phenomenology studies different fields of human life. In any kind of experience (affective, axiological, etc.) the naively transcendent objectivity can be traced back to the principles and a priori laws that make them possible. Husserl, thus, envisions the project of a critique of reason in its totality, not limited to knowledge but extended to all domains of subjective experience ${ }^{24}$.

\section{Conclusion}

I tried to show that, around 1906, Husserl presents phenomenology as an investigation which is far from following the mathematical developments of pure logic, but which aims at clarifying the eidetic laws that illuminate the meaning and possibility of the correlation between subjective acts and intentional objects in every realm of experience. This is the general project whereby phenomenology is conceived as an autonomous transcendental discipline. However, there are some problems in this project. As a transcendental investigation, phenomenology must not use any pre-given knowledge whose possibility is not clarified. Thus, all objective sciences are suspended and cannot offer any data to the phenomenologist. But what about pure logic? This science studies the basic concepts and propositional forms by which any cognitive judgment can be correctly formulated. In the Prolegomena, pure logic and phenomenology complement each other, and this indicated a relationship of mutual foundation. On the one hand, phenomenology reveals the noetic conditions of evidence that are valid for all sciences, included pure logic. On the other, pure logic analyses the formal principles whereby phenomenology itself 
is formulated. However, under the transcendental reflection, this complementarity is broken, since phenomenology should not presuppose any kind of objective knowledge, even that of pure logic. A problem arises here: would not the suspension of pure logic entail that phenomenology could not use logical principles? Well, obviously Husserl proposes coherent descriptions of consciousness, wherein the logical principles of correct enunciation are respected. Thus, it seems that logic cannot be put into brackets, and at least regarding this discipline phenomenology is not completely independent from it.

I think that the thorny problem at stake here is not solved in ILTK. As we have seen, in this text the requirement of presuppositionlessness as a mark of transcendental investigation already is at work (cf. ILTK 362-364; Hua XXIV 368-370). But there is still no detailed consideration on the role of basic logic rules (systematized by pure logic) as presuppositions of the phenomenological discourse. It seems that Husserl will present publically a satisfactory solution to this problem only in $\S 59$ of Ideas I. There, he states that although the transcendental investigation should not presuppose pure logic as a datum, it does not mean that its results are illogical, since the most basic logical principles are immediately attested in experience and given with absolute evidence. Thus, these basic logical principles are not presuppositions of the phenomenological description of experience, but, on the contrary, they are intuitively posited in this description. Based on these evident principles, phenomenology can formulate its theses, which, in general, do without complex deductive chains. Thus, it is true that around 1906-7 transcendental phenomenology is already conceived as independent of the objective validity of pure logic. However, the full clarity regarding what is implied in this independence (e.g., how to warrant the logical coherence of the transcendental description so conceived) took some years to be grasped by Husserl. 


\begin{abstract}
Notes
${ }^{1}$ I mention just some few examples of the remarkable studies that are devoted to different features of this topic: Sokolowski (1970); De Boer; Ströker; Bernet, Kern and Marbach; Mohanty (1995, 2008); Moran; Luft; Lavigne; Follesdal.

${ }^{2}$ Some authors already faced this theme, although not relating the Prolegomena of Pure Logic to Introduction to Logic and Theory of Knowledge, as I intend to do here. Cf. Fisette; Schérer (chap. 1-2).
\end{abstract}

${ }^{3}$ Cf. Hua III/I, §56, §59, §60. I shall discuss the meaning of mathesis universalis in the next section.

${ }^{4}$ I will not deal with the problem of psychologism in this article. Excellent discussions of this topic are Kusch; Hanna.

5 In the citations, when only a section number is referenced, the German Husserliana edition (Hua) is cited alone. However, when specific pages are referenced, then the English translation precedes the Husserliana edition reference.

${ }^{6}$ This is how Husserl presents the task of pure logic thus conceived: "to deal with the sciences as systematic unities of this or that sort in other words, with the formal features that stamp them as sciences, with the features that determine their mutual boundaries and their inner articulation into fields, into relatively closed theories, with the features which fix their essentially different species or forms etc." (Logical Investigations 24; Hua XVIII 40). One should notice that Husserl found inspiration for his project in Bolzano's Wissenschaftslehre. There, one finds "excellent thoughts related to the circumscription of our discipline" (Logical Investigations 27; Hua XVIII 43), he states. That work, from 1837, "in its treatment of the logical 'theory of elements,' far surpasses everything that world-literature has to offer in the way of a systematic sketch of logic" (Logical Investigations 142; Hua XVIII 227). However, Husserl notes that Bolzano's work lacks investigations "which give genuine philosophical intelligibility to the logical functions of thought, and so provide a philosophical estimate of logic as a discipline" (Logical Investigations 143; Hua XVIII 228). The specificity of Husserl's work will be exactly the incorporation of a philosophical elucidation of logic, as we shall see.

7 "Mathematical" is here used in the sense of deductive standards of validity and not in the sense of categories of quantity.

8 "The extraordinarily difficult task of pure logic is, on one side, to analytically ascend to the axioms that, as starting-points are indispensable and also irreducible to one another without a direct or reflective circle; and, after that, to construct and to arrange the deductions for the logical theorems ... so that at each step not only the premises but also the principles of deductive transitions are either among the axioms or among the previously proven theorems" (Logical Investigations 107; Hua XVIII 170). 
${ }^{9}$ Regarding this topic, see Smith.

${ }^{10}$ Husserl admits that the definition of scientificity as a deductive systemic unity of propositions derived from apodictic principles cannot be fully fulfilled for all existing sciences. Only abstract or nomological sciences (which suppose a priori laws as unifying principles) can properly express such logical content of scientificity. Those sciences (formal Mathematics, mathematical Physics, a priori Mechanics, etc.) are developed on the sole basis of categorical and ontological pure concepts, without any reference to a determinate material region. This is not what happens with empirical sciences, which are always opened to new evidence acquired by experience. Yet, Husserl believes there should be an ideal theoretical character ruling over the development of those theories, namely, the laws of probability (Hua XVIII, §72). In the present article I shall not explore the difficulties concerning the role of empirical sciences in the doctrine of science. Moreover, it is not completely clear in the Prolegomena what the theoretical specificity of phenomenology itself is. Husserl presents phenomenology as a descriptive discipline, as we shall see, but he does not discuss extensively the relationships between the phenomenological description and the validation methods studied by the doctrine of science. It seems to me that this topic will be explicitly developed by Husserl only in $§ 71-75$ of Ideas I. I am also not exploring this topic in this article.

11 "As far as evidence extends, the concept of knowledge extends also" (Logical Investigations 18; Hua XVIII 29).

12 "By the subjective conditions of possibility, we do not mean here real conditions rooted in the individual judging subject, or in the varied species of judging beings (e. g. human beings), but ideal conditions whose roots lie in the form of subjectivity as such, and in its relation to knowledge. We shall distinguish them by speaking of noetic conditions" (Logical Investigations 76; Hua XVIII 119).

${ }^{13}$ As R. Schérer already noted years ago, "the problem around which phenomenology is born is that of the nature of subjectivity to which truth can be given as such" (28).

${ }^{14} \mathrm{H}$. Spiegelberg points out that, besides authors of the Hegelian school, Brentano, Mach and Hering already used the term before Husserl, though with a different meaning (Spielberg 8, 27-8, 53).

15 In the first edition Husserl refers to the "logical origin" (Hua XVIII, §67, 246). The change to "phenomenological origin" makes explicit that the subject here is the investigation of the pure subjective source of logical categories.

16 "The mathematician constructs theories of numbers, quantities, inferences, manifolds, without needing to have ultimate insight into the essence of theory in general, and that of the concepts and laws which are its conditions" (Logical Investigations 159; Hua XVIII 255). 
${ }^{17}$ When he presents the natural attitude, in 1907, Husserl mentions "earlier lectures" (Hua II 17) in which the distinction between this attitude and the philosophical one would have already been made. So in The Idea of Phenomenology Husserl recognizes that the distinction between transcendental and natural sets of problems was already established probably in ILTK.

${ }^{18}$ In the conclusion, I will briefly discuss one difficulty related to this point.

19 "Even if we are actually doubtful about [the existence of nature], though, one thing is certain: that now, while I am doubting or questioning, such and such perceptions (namely those actually performed) exist, that in them such and such objects appear to me, likewise, that the thought 'natural science' exists, that natural science exists as a phenomenon, and if I have precisely called one theory or another to mind, these theory phenomena exist. Any sciences whatsoever, any theories whatsoever, any knowledge whatsoever exist, not as validities, but as claims to validity, as validity phenomena" (ILTK 195; Hua XXIV 198-9).

${ }^{20}$ Sokolowski (1987) and Tieszen highlight that in ILTK Husserl presents the phenomenological reduction in a considerable developed way probably for the first time in his career. I agree with them and, consequently, not with Lee Hardy's (translator of The Idea of Phenomenology) following statement: "the first public exposition of the motivation, sense, and implications of Husserl's newly discovered method - called the 'phenomenological reduction' or, alternatively, the 'epistemological reduction'-was presented in five lectures later published under the title, Die Idee der Phänomenologie" (2).

21 The sphere of pure evidence opened by phenomenological reduction is not limited to subjective acts, but also encompasses, as Husserl puts it, "in a certain way every object, despite its transcendence" (ILTK 227; Hua XXIV 231). Although any consideration about the transcendent existence of objects is avoided, all possible objects can now be taken as intuitive data, that is, as phenomena in correlation with the acts directed to them as they are manifestly evident.

22 "We must go back to the original sources of clarity and essentiality, where proposition, truth, falsehood, contradiction, and thus all concepts and conceptual relations concerned here, stand before our eyes in authentic, intuitive givenness, and we can behold in general ways that this circumstance is grounded in the essence given as a given and inseparable from it. If I have seen that, then I am in possession of an absolute truth, of a truth that is grounded purely in itself and is not amenable to any relativization to I and world and any contingent sphere of individuality" (ILTK 231; Hua XXIV 235-6).

23 "So far, we have been exclusively guided by epistemological interests and, if the critical problems were to be solved, this called for the elimination of all natural objectifications, of all empirical judgments, therefore, for the phenomenological reduction. After we have reached phenomenological ground, however, we readily see that a distinctive kind of theoretical interest can be directed toward everything that is to be explored here, an interest that does not seek to 
acquire and treat phenomenological knowledge simply in the service of problems of critique of knowledge" (ILTK 212; Hua XXIV 217).

24 "All reason in the a posteriori has its principles a priori, and these principles are the grounds of justification of the objective, unconditional validity that every operation of so-called reason claims in both the theoretical and axiological spheres. Bringing principles to light everywhere and testing their authenticity, solving transcendental problems regarding them, therefore tracing them back to their phenomenological origin and meaning, showing them in the realm of intuitive essences to be the authentic matrix of knowledge as givens of seeing reason, or rejecting them as absurdities, that is the true philosophical task" (ILTK 233; Hua XXIV 237).

\section{Works Cited}

\section{Husserl, Edmund:}

\section{Husserliana Editions (Hua)}

Hua II: Die Idee der Phänomenologie. Ed. Walter Biemel. The Hague: Martinus Nijhoff, 1973.

Hua III/I: Ideen zu einer reinen Phänomenlogie und phänomenlogischen Philosophie. Erstes Buch. Ed. Karl Schuhman. The Hague: Martinus Nijhoff Publishers, 1977.

Hua XVIII: Logische Untersuchungen. Erster Teil: Prolegomena zur reinen Logik. Ed. Elmar Holenstein. The Hague: Martinus Nijhoff, 1975.

Hua XIX/I: Logische Untersuchungen. Zweiter Teil. Untersuchungen zur Phänomenologie und Theorie der Erkenntnis. Band I. Ed. Ursula Panzer. The Hague: Martinus Nijhoff, 1984.

Hua XXIV: Einleitung in die Logik und Erkenntnistheorie. Vorlesungen 1906/07. Ed. Ullrich Melle. The Hague: Martinus Nijhoff, 1985.

\section{Translations}

Ideas Pertaining to a Pure Phenomenology and to a Phenomenological Philosophy. First Book: General Introduction to a Pure Phenomenology. Trans. F. Kersten. The Hague: Martinus Nijhoff Publishers, 1983. Translation of Hua III/I.

Introduction to Logic and Theory of Knowledge. Trans. O. C. Hill. Dordrecht: Springer, 2008. Translation of Hua XXIV. 
Logical Investigations. Vol. I. Trans. J. N. Findlay. London: Routledge, 2001. Translation of Hua XVIII and XIX/I.

The Idea of Phenomenology. Trans. L. Hardy. Dordrecht: Kluwer, 1999. Translation of Hua II.

\section{Other Works:}

Bernet, R., Kern, I., and Marbach, E. Edmund Husserl. Darstellung seines Denkens. Hamburg: Felix Meiner, 1989.

De Boer, T. The Development of Husserl's Thought. The Hague: Martinus Nijhoff, 1978.

Fisette, D. "Husserl's Programme of a Wissenschaftslehre in the Logical Investigations." Husserl's Logical Investigations Reconsidered. Ed. D. Fisette. Dordrecht: Kluwer Academic Publishers, 2003. 35-57.

Follesdal, D. "Husserl's Reductions and the Role they Play in his Phenomenology." A Companion to Phenomenology and Existentialism. Ed. H. Dreyfus and M. Wrathall. Oxford: Blackwell, 2006.105-114.

Hanna, R. "Husserl's Arguments against Logical Psychologism (Prolegomena, §§ 17-61)." Edmund Husserls Logische Untersuchungen. Hrsg. V. Mayer. Berlin: Akademie Verlag, 2008. 27-42.

Hardy, L. “Translator's Introduction.” The Idea of Phenomenology by Edmund Husserl. Dordrecht: Kluwer Academic Publishers, 1999. 1-13.

Kusch, M. Psychologism. London: Routledge, 1995.

Lavigne, J. F. Husserl et la naissance de la phenomenology (1900-1913). Paris: PUF, 2005.

Luft, S. "Husserl's Notion of the Natural Attitude and the Shift to Transcendental Phenomenology.” Analecta Husserliana, Vol. 80 (2002): 114-119.

Mohanty, J. "The Development of Husserl's Thought." The Cambridge Companion to Husserl. Ed. B. Smith and D. W. Smith. Cambridge: Cambridge Univiversity Press, 1995. 45-77.

—. The Philosophy of Edmund Husserl. New Haven: Yale Univ. Press, 2008.

Moran, D. Introduction to Phenomenology. London: Routledge, 2000.

Schérer, R. La Phénoménologie des 'Recherches Logiques’ de Husserl. Paris: PUF, 1967. 
Smith, D. W. "'Pure' Logic, Ontology and Phenomenology.” Revue Internationale de Philosophie, Vol. 2, no. 224 (2003): 133-156.

Sokolowski, R. The Formation of Husserl's Concept of Constitution. Haag: Martinus Nijhoff, 1970.

—. "Review of Einleitung in die Logik und Erkenntnistheorie. Vorlesungen 1906-07.

Husserliana XXIV by E. Husserl." The Review of Metaphysics, Vol. 40, no. 4 (1987): 779-781.

Spiegelberg, H. The Phenomenological Movement. An Historical Introduction. The Hauge: Martinus Nijhoff Publishers, 1960.

Ströker, E. Husserls transzendentale Phänomenologie. Frankfurt: Vittorio Klostermann, 1987.

Tieszen, R. "Review of Introduction to Logic and Theory of Knowledge: Lectures 1906/07 by E. Husserl.” Philosophia Mathematica, Vol. 18, no. 2 (2010): 247-252. 